\title{
Dissociable Influences of Opiates and Expectations on Pain
}

\author{
Lauren Y. Atlas, ${ }^{1}$ Robert A. Whittington, ${ }^{2}$ Martin A. Lindquist, ${ }^{4}$ Joe Wielgosz,${ }^{5}$ Nomita Sonty,,${ }^{2,3}$ and Tor D. Wager \\ ${ }^{1}$ Department of Psychology, New York University, New York, New York 10003, ${ }^{2}$ Department of Anesthesiology and ${ }^{3}$ Department of Psychiatry, Columbia \\ University, New York, New York, 10032, and ${ }^{4}$ Department of Statistics, Columbia University, New York, New York 10027, ${ }^{5}$ Department of Psychology, \\ University of Wisconsin, Madison, Wisconsin 53706, and ${ }^{6}$ Department of Psychology and Neuroscience, University of Colorado, Boulder, Colorado 80309
}

Placebo treatments and opiate drugs are thought to have common effects on the opioid system and pain-related brain processes. This has created excitement about the potential for expectations to modulate drug effects themselves. If drug effects differ as a function of belief, this would challenge the assumptions underlying the standard clinical trial. We conducted two studies to directly examine the relationship between expectations and opioid analgesia. We administered the opioid agonist remifentanil to human subjects during experimental thermal pain and manipulated participants' knowledge of drug delivery using an open-hidden design. This allowed us to test drug effects, expectancy (knowledge) effects, and their interactions on pain reports and pain-related responses in the brain. Remifentanil and expectancy both reduced pain, but drug effects on pain reports and fMRI activity did not interact with expectancy. Regions associated with pain processing showed drug-induced modulation during both Open and Hidden conditions, with no differences in drug effects as a function of expectation. Instead, expectancy modulated activity in frontal cortex, with a separable time course from drug effects. These findings reveal that opiates and placebo treatments both influence clinically relevant outcomes and operate without mutual interference.

\section{Introduction}

Opiate analgesics are some of the oldest members of modern medicine's pharmacopeia (Brownstein, 1993). Opioids relieve acute and chronic pain (Ballantyne and Mao, 2003) and reduce activation in pain-related brain regions (Wise et al., 2002, 2004). When patients are treated with analgesics, however, treatment is nearly universally "open-label, " with full knowledge that a helpful drug is being given. Thus, therapeutic outcomes reflect not only specific pharmacological effects, but also psychological factors (placebo effects), such as beliefs about treatment (Benedetti et al., 2011).

To account for psychological factors, clinical trials assume that placebo effects are independent of drug effects and can be "subtracted away" to reveal the true drug effect (Beecher, 1955). Thus, in randomized controlled trials (RCTs), patients are randomly assigned to receive active drug treatment or placebo control, and differences in outcomes are attributed to the drug. This isolates pure drug effects only if drug and placebo effects are additive, i.e., if (1) expectations and other nonspecific factors are identical for each group, and (2) drug effects are the same whether or not a patient believes she has received the drug. How-

Received Jan. 17, 2012; revised March 17, 2012; accepted April 20, 2012.

Author contributions: L.Y.A., R.A.W., N.S., and T.D.W. designed research; L.Y.A., R.A.W., J.W., and T.W. performed research; L.Y.A., M.A.L., and T.D.W. contributed unpublished reagents/analytic tools; L.Y.A. and T.D.W. analyzed data; L.Y.A., R.A.W., M.A.L., J.W., N.S., and T.D.W. wrote the paper.

This work was funded by NIMH R01MH076136 and NIDA R01DA027794 (PI T.D.W.) and by internal funding from the Department of Anesthesiology at Columbia University. We thank Steve Shafer for assistance with the pharmacokinetic-pharmacodynamic model, Namema Amendi, Kate Dahl, and Stephen Dashnaw for assistance with data collection, Ethan Kross and Damon Abraham for providing data for the pain-processing network localizer, and Daphna Shohamy and Lauren Leotti for comments and discussion.

Correspondence should be addressed to Lauren Atlas, New York University, Meyer Hall, 6 Washington Place, Room 877, New York, NY 10003. E-mail: laurenatlas@nyu.edu.

DOI:10.1523/JNEUROSCI.0383-12.2012

Copyright $\odot 2012$ the authors $\quad 0270-6474 / 12 / 328053-12 \$ 15.00 / 0$ ever, if drug effects differ as a function of belief, then RCT-based estimates may be biased. Placebo and opioid analgesia both target the opioid system (Levine et al., 1978; Eippert et al., 2009) and affect opioid-rich medial prefrontal-subcortical circuits (Petrovic et al., 2002). These common mechanisms could lead to placebo-drug interactions, or beliefs and opioid analgesics could modulate pain through separate neurobiological processes when combined, leading to additive, dissociable effects.

As of yet, no studies have examined the relationship between expectations and analgesic drugs and tested for the presence or absence of interactions. One recent study showed that expectancies influence pain and pain-related brain responses in the presence of a fixed concentration of the $\mu$-opioid agonist remifentanil (Bingel et al., 2011). However, drug levels were not manipulated, and therefore observed expectancy effects may have been additive with drug effects, consistent with the assumptions underlying clinical trials, or may have reflected placebo-drug interactions. To test the critical question of whether drug effects differ as a function of belief, both drug and expectancy must be manipulated.

In two studies, we examined the relationship between opioid analgesia and placebo analgesia by manipulating expectations and remifentanil concentration. We used a balanced placebo design (Ross et al., 1962; Rohsenow and Marlatt, 1981) to test for potential interactions between expectations about treatment (placebo) and remifentanil on pain reports (see Materials and Methods, Behavioral experiment). In a separate experiment (see Materials and Methods, fMRI experiment), we administered intravenous remifentanil during fMRI scanning in an open-hidden design (Colloca et al., 2004) to test whether the physiological effects of remifentanil differ as a function of treatment context (open vs hidden administration). We modeled the brain concentration of remifentanil over time using a pharmacokinetic model 
(Minto et al., 1997b; Minto et al., 1997a). Critically, this allowed us to isolate drug effects and expectancy effects on pain reports and brain activation, and to test whether or not they interact to affect pain processing.

\section{Materials and Methods}

Behavioral experiment

Participants. Fifteen healthy, right-handed English-speaking participants were enrolled in the behavioral experiment. One participant experienced nausea and did not complete the session, leaving a final sample of $n=14$ (7 female; mean age, 22). All participants gave informed consent as approved by Columbia University's Institutional Review Board and were fully debriefed after the session. Participants were not enrolled if they reported a history of neurological or psychiatric disorders, psychoactive substance abuse, or prior treatment with opiates, and were screened for illicit drugs using a commercial urine drug test.

Thermal stimulation and pain ratings. Thermal stimulation was delivered to the volar surface of the left inner forearm using a $16 \times 16 \mathrm{~mm}$ Peltier thermode (Medoc). Each stimulus lasted $10 \mathrm{~s}$ (10 s; $1.5 \mathrm{~s}$ ramp up and down, $7 \mathrm{~s}$ at peak). Temperatures were individually calibrated using an adaptive, randomized procedure, as described in previous work (Atlas et al., 2010). Participants rated stimulation on a continuous, numerically anchored visual analog scale (VAS) from 0 to 8 ( 0 , no sensation; 1 , nonpainful warmth; 2 , low pain; 5 , moderate pain; 8 , maximum tolerable pain). During testing, we applied temperatures calibrated to elicit levels of low pain (VAS rating $=2 ; M=40.71^{\circ} \mathrm{C}, \mathrm{SD}=2.83$ ), low-medium pain (VAS rating $=4 ; M=43.11^{\circ} \mathrm{C}, \mathrm{SD}=2.33$ ), medium-high pain (VAS rating $=6 ; M=44.3^{\circ} \mathrm{C}, \mathrm{SD}=1.60$ ), and high pain (VAS rating $=$ $8 ; M=47.25^{\circ} \mathrm{C}, \mathrm{SD}=1.31$ ). The pain rating scale we used is advantageous in that it is simple and provides reliable, repeated measurements for a wide range of individuals (Chapman et al., 1985; Bijur et al., 2001) in a few seconds during scanning. A disadvantage is that the scale is unidimensional. Previous work has shown that some opioid analgesics may specifically target pain unpleasantness, without affecting pain intensity ratings (Yang et al., 1979; Price et al., 1985; Kupers et al., 1991; Cohen et al., 2008), although other studies have shown opposite effects (Gracely et al., 1979). To acknowledge this potential dissociation, we collected summary ratings of overall pain intensity, unpleasantness, and pleasantness immediately following each run in the behavioral experiment.

Remifentanil administration and pharmacokinetic modeling. All participants received intravenous remifentanil $(10 \mu \mathrm{g} / \mathrm{ml}$ concentration $)$ at a steady dose of $0.04 \mu \mathrm{g} / \mathrm{kg} / \mathrm{min}$ during Open and Hidden administration (see below, Experimental paradigm). This dose was established as the effective dose (ED-50) for achieving remifentanil-induced analgesia without producing overt sedation based on individually calibrated doses in the fMRI experiment (which was collected before the behavioral experiment).

We used the three-compartment pharmacokinetic model of remifentanil (Minto et al., 1997a,b) to estimate the predicted brain concentration for each participant, over time. The model incorporates parameters for the transfer of drug between plasma, fast tissue (e.g., brain tissue), and slow tissue (e.g., fat). The estimated effect site concentration across time is a function of dose (in $\mu \mathrm{g} / \mathrm{kg} / \mathrm{min}$ ), age, gender, and lean body mass. For each participant, we estimated the expected brain concentration of remifentanil, and then normalized this regressor to reflect percentage of maximum concentration at each time point. Maximum absolute concentration was modeled at the subject level in group-level analyses. The fixed dose of $0.04 \mu \mathrm{g} / \mathrm{kg} / \mathrm{min}$ corresponded to an average maximum absolute concentration of $0.761 \mathrm{ng} / \mathrm{ml}$ during the fMRI session, which is similar to the fixed dose of $0.8 \mathrm{ng} / \mathrm{ml}$ applied in previous work that used target-controlled infusion (Bingel et al., 2011).

Experimental paradigm. Participants experienced four test runs (Fig. 1): two during remifentanil administration, and two during a control infusion $(0.9 \%$ saline). The remifentanil manipulation was crossed with a manipulation of expectations about the infusion: On two runs (one remifentanil and one control), participants were told they would receive remifentanil, and on the other runs participants were told that they would receive no drug. This $2 \times 2$ factorial ANOVA design produced

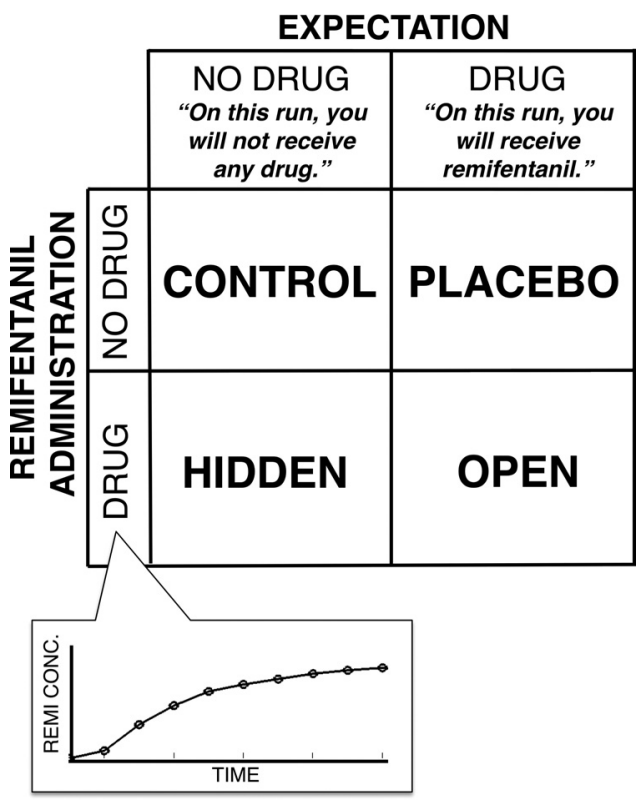

Figure 1. Balanced placebo design. We used a full factorial, balanced placebo design to examine the relationship between remifentanil analgesia and expectancy-based (placebo) analgesia in the behavioral experiment. Remifentanil was delivered during Hidden and Open administration with the pharmacokinetic profile pictured in the inset. Subjects were told that they would receive remifentanil during Placebo and Open conditions, and were told that they would receive no drug during Control and Hidden administration.

four conditions tested for each participant: Open administration (Expect drug, receive drug), Hidden administration (Expect no drug, receive drug), Placebo (Expect drug, receive no drug), and Control (Expect no drug, receive drug). Testing order was counterbalanced across participants. Main effects of Expectancy were assessed with the contrast (Open + Placebo - Hidden - Control). Main effects of Drug were assessed with the contrast (Open + Hidden - Placebo Control). The interaction was assessed with the standard interaction contrast (Open + Control - Placebo - Hidden).

During the infusion period on each run, participants experienced 18 thermal pain trials: 3 high pain trials, 6 high-medium trials, 6 lowmedium trials, and 3 low pain trials. The infusion period began with the first trial and lasted 13.5 min per run. As described below (Behavioral analysis), we included all trials in our analysis, and controlled for temperature. Stimulation was preceded by a $2 \mathrm{~s}$ auditory predictive cue (a pure tone of 500 or $1000 \mathrm{~Hz}$ ) that gave information about the upcoming noxious heat intensity [as in the study by Atlas et al. (2010)], and a $6 \mathrm{~s}$ anticipatory delay period. Participants rated perceived pain immediately following pain offset on every trial. Between trials, participants performed three trials of a visual letter detection task, with the difficulty individually calibrated for each participant, to monitor attention and alertness. We focused on analyses of pain reports as a function of Temperature, Drug (estimated remifentanil concentration), and Expectancy. Effects of pain-predictive cues and attention task results will be reported separately. We note that there were no interactions between painpredictive cues and Drug and/or Expectancy, nor was attention task performance modulated by Drug or Expectancy. Participants provided ratings of overall intensity, pleasantness, and unpleasantness (see above) at the end of each run, before the drug washout period.

A $7 \mathrm{~min}$ washout period followed drug infusion to minimize the amount of remifentanil in the participant's system at the start of the next run. Based on the pharmacokinetic model, the expected brain concentration of remifentanil at this point was $0.11 \mathrm{ng} / \mathrm{ml}$ at this point, or $14 \%$ of maximum drug concentration.

Following the experiment, most participants $(N=12)$ completed a structured debriefing interview. We included questions designed to determine whether participants suspected deception, as well as a forced choice task to assess whether participants could determine when they had 
received remifentanil versus saline, regardless of whether they suspected deception. Only three participants reported suspecting deception before debriefing, and 7 of 12 performed correctly on the forced choice task (not significantly different from chance).

Behavioral analysis. Behavioral data were analyzed with a linear mixedeffects model using the mixed procedure in Statistical Analysis Software 9.1 (SAS; SAS Institute). We analyzed pain ratings as a function of estimated brain concentration of Remifentanil (continuous), Expectancy (expect drug vs expect no drug), and Temperature, and predicted interactions. We also modeled a linear effect of Run to test for habituation across the session. Finally, we included a predictor reflecting maximum drug concentration at the subject level. Remifentanil, Expectancy, and average pain (the intercept) were modeled as random variables, to account for potential individual differences in the magnitude of these effects.

\section{FMRI experiment}

Participants. Twenty-four participants participated in the fMRI experiment. Two experienced nausea during the session, and technical malfunctions resulted in the loss of imaging data from one participant, leaving $n=21$ ( 11 female; mean age, 24.7 years). Behavioral data from two additional participants were not recorded due to technical malfunctions, leaving $n=19$ for behavioral analyses (10 female; mean age, 24.4 years).

Thermal stimulation and pain ratings. Thermal stimulation was applied to the left volar forearm with the same device, calibration, and rating scale described above. In the fMRI experiment, applied temperatures were calibrated to elicit levels of low pain (VAS rating $=2 ; M=41.16^{\circ} \mathrm{C}, \mathrm{SD}=2.64$ ) and high pain (VAS rating $=8 ; M=47.05^{\circ} \mathrm{C}, \mathrm{SD}=1.69$ ) only, to maximize the number of high-pain trials of critical interest.

Remifentanil dosing procedure. Because we ran the fMRI experiment first, this study included a more extensive remifentanil dosing procedure. Following pain calibration, a titration procedure was used to determine a dose of remifentanil that elicited analgesia without sedation for each participant. Before the dosing procedure, most participants $(N=17)$ rated expected analgesic efficacy $(0$, not effective at all; 10 , most effective imaginable) and confidence in those ratings. Then, an intravenous catheter was inserted, and we infused $10 \mu \mathrm{g} / \mathrm{ml} \mathrm{remifentanil} \mathrm{at} \mathrm{a} \mathrm{steady} \mathrm{dose}$ for three-min intervals. High-pain stimulation (VAS Level 8) was applied every $15 \mathrm{~s}$ throughout each $3 \mathrm{~min}$ infusion, and we rotated through the six skin sites twice, for a total of 12 stimuli per dose. Participants made VAS ratings after each stimulus and verbal reports of changes in sensation (changes in physical sensation, psychological state, or alertness) every three trials. We monitored heart rate, blood pressure, and visual signs of sedation (e.g., eyelid closure) throughout the session. All participants received the following four doses in the following order: (1) 0.025 $\mu \mathrm{g} / \mathrm{kg} / \mathrm{min}$, (2) $0.04 \mu \mathrm{g} / \mathrm{kg} / \mathrm{min}$, (3) $0.05 \mu \mathrm{g} / \mathrm{kg} / \mathrm{min}$, (4) $0.06 \mu \mathrm{g} / \mathrm{kg} / \mathrm{min}$. We also tested intermediate doses as necessary. On average, subjects reported a decrease of 0.83 on the pain rating scale for each $0.01 \mu \mathrm{g} / \mathrm{kg} /$ min unit increase in dose.

Following the dosing procedure, the selected dose was administered for $5 \mathrm{~min}$ to ensure that the participant would be able to stay alert during the $\mathrm{fMRI}$ scans. Based on this procedure, the average dose selected for use during the fMRI portion was $0.043 \mu \mathrm{g} / \mathrm{kg} / \mathrm{min}(\mathrm{SD}=0.01)$. Individually titrated doses corresponded to an average maximum absolute concentration of $0.884 \mathrm{ng} / \mathrm{ml}$ during the fMRI session, and we controlled for maximum absolute concentration at the subject level in group-level analyses. Following dosing, participants again rated analgesic expectancy and then began the fMRI portion of the experiment.

Physiological measurements. During fMRI scanning, we used fMRIcompatible equipment to monitor and record continuous physiological measurements, including heart rate, peripheral pulse, systolic and diastolic blood pressure every 5 min (between scanning runs; In vivo Magnitude), respiration rate, saturation of peripheral oxygen (SPO2), end-tidal $\mathrm{CO}_{2}$, and skin conductance (James Long Company). Finally, visual stimuli were presented through goggles positioned upon the scanner head coil (Avotech), which allowed us to monitor participant alertness, eye position, and pupil dilation (SensoMotoric Instruments). Because remifentanil was administered identically under Open and Hid- den conditions, we infer that any differences in pain-evoked BOLD responses are due to our psychological manipulation, rather than physiological changes associated with the drug. Therefore, only behavioral and brain measures were included in the analyses presented here.

Experimental paradigm. Participants underwent two runs of fMRI scanning during remifentanil infusion (Fig. $2 \mathrm{~A}$ ), in counterbalanced order. In the Open run, participants were told that they would receive remifentanil, and saw a visual prompt informing them of the start and end of the infusion period. In the Hidden run, participants were told that they would not receive any drug. While the behavioral experiment used a factorial balanced placebo design, requiring the inclusion of Placebo and Control as separate conditions, the design of the fMRI experiment included preinfusion and postinfusion baseline periods in an off-on-off design. This allowed us to separate the time courses of expectancy and drug concentration as described below (see Orthogonalized parametric regressors), and ensure that both were independent of habituation. As in the behavioral experiment, we used a thermal pain model and collected pain reports on every trial.

Structural images (10 min duration) were acquired between runs to ensure that no remifentanil was circulating in the participant's system at the start of the second run. Based on pharmacokinetic models, the average drug concentration following the structural scan was 0.066 $\mathrm{ng} / \mathrm{ml}$, or $7 \%$ of total drug concentration. We controlled for order in all analyses in case this small amount of residual remifentanil influenced brain or behavioral responses during the second run, as well as to assess whether there was an effect of experimental order (OpenHidden vs Hidden-Open)

Each run was composed of six blocks: a preinfusion baseline, three blocks of remifentanil infusion at the dose determined during calibration, and two blocks after infusion (washout). Each block consisted of six alternating low and high pain stimulations, with order counterbalanced across participants (Low-High vs High-Low). We used one of the six predetermined skin sites for each scanning block to avoid skin damage. The experimenter moved the thermode during a $30 \mathrm{~s}$ delay period that separated each block. Skin sites were tested in the same order in Hidden and Open runs. Participants rated perceived pain on every trial using the VAS described above and an fMRI-compatible trackball (Resonance Technologies).

On each trial, participants saw a cue ( $3 \mathrm{~s})$ that provided information about upcoming heat intensity ("Hot" or "Warm"). This was followed by a 7-13 s jittered anticipation period $(M=10.16 \mathrm{~s}, \mathrm{SD}=2.64)$, and $10 \mathrm{~s}$ of noxious stimulation ( $1.5 \mathrm{~s}$ ramp up, $7 \mathrm{~s}$ at peak, $1.5 \mathrm{~s}$ return to baseline). A $9-15 \mathrm{~s}$ jittered interstimulus interval (ISI; $M=11.67 \mathrm{~s}$, SD $=2.50$ ) followed pain offset, and then participants rated pain on a VAS that was displayed for either 4 or $6 \mathrm{~s}(M=18 \mathrm{~s}, \mathrm{SD}=0.98)$. Auditory tones accompanied the cue and rating prompt to ensure participants remained alert and rated pain on each trial. A $9-15 \mathrm{~s}$ jittered ISI $(M=11.46 \mathrm{~s}, \mathrm{SD}=$ 2.57) separated the rating from the start of the next trial.

Behavioral analysis. Our analyses focused on identifying how expectancies contribute to analgesia under standard Open drug administration. We hypothesized that pain reports may be affected by several critical factors: (1) drug effects, i.e., effects that parallel the pharmacokinetic profile of remifentanil; (2) context-related expectancies (average effects of Open vs Hidden across time); (3) instruction-related expectancies, i.e., decreases in Open administration specifically during the infusion period; and (4) Drug $\times$ Context interactions, i.e., (Open Drug versus Hidden Drug), which estimates the interaction of Open versus Hidden context and remifentanil concentration, and tests whether expectancies enhance drug effects.

We tested these effects using multilevel, linear mixed effects models implemented in Matlab, treating the participant as a random variable. We modeled each of the effects described above at the first (withinsubject) level, though we do not interpret Context-related expectancies here because we did not have a priori hypotheses about differences occurring outside of the Infusion period. As in the behavioral experiment, Drug effects were modeled with a continuous, parametric regressor reflecting predicted brain remifentanil concentration (Fig. $2 A$ ) (Minto et al., 1997a,b). Context-related expectancies were modeled with an effectscoded regressor with values of 1 for Open and -1 for Hidden adminis- 
tration. Instruction-related expectancies were modeled as a simple boxcar, with 0 coded for events preinfusion and postinfusion, and 1 coded for events during the infusion period. The interaction between Drug concentration and Context tested the (Open Drug vs Hidden Drug) effect. We also modeled Habituation within-subjects as a linear effect of time, both within each block and across the entire session. At the second level (between-subject), we included covariates for maximum absolute drug concentration and testing order, to ensure that our within-subjects effects did not differ as a function of total dose or counterbalancing. Trials on which participants failed to make a response $(M=4.53, \mathrm{SD}=6.34)$ were not included in the behavioral analysis.

We analyzed two behavioral models: the first included all trials, and included temperature effects and interactions with temperature, and the second (consistent with our imaging analyses) focused on high intensity trials, as we were most interested in whether and how remifentanil and expectancy influenced responses to painful events. Results are reported with one-tailed $p$ values, as we expected drug- and expectancyinduced decreases, and temperature-related increases.

Orthogonalized parametric regressors. We tested two variants of each of the two models described above. We expected that instructions accompanying the start and end of the infusion period would induce expectations of relief that precede the brain drug concentration, which would lead to pain modulation during Open administration above and beyond that accounted for by Drug effects. To estimate the effects uniquely attributable to expectancies, the Instruction-related expectancy regressor was orthogonalized with respect to the Drug concentration regressor (Büchel and Friston, 1997). We refer to this as the "Infusion period orthogonalized" effect (Fig. $2 B$ ), and this parallels the parametric neuroimaging analyses described below. However, because this procedure assigns the variance shared by drug and expectancy effects to the drug, we tested a second variant (Drug period orthogonalized), in which the drug regressor was orthogonalized with respect to the instructionrelated expectancy regressor, allowing us to assess effects uniquely attributable to the drug.

\section{FMRI acquisition and analysis}

Data acquisition. Whole-brain fMRI data were acquired on a 1.5T GE Signa Twin Speed Excite HD scanner (GE Medical Systems) at Columbia University, using an echo-planar imaging sequence (TR $=2000 \mathrm{~ms}$, $\mathrm{TE}=34 \mathrm{~ms}$, field of view $=224 \mathrm{~mm}, 64 \times 64$ matrix, $3.5 \times 3.5 \times 4.0 \mathrm{~mm}$ voxels, 28 slices). Each run lasted $33 \mathrm{~min}$ and $20 \mathrm{~s}$ (1000 TRs), divided into six blocks, with a brief pause in scanning after the fourth block to prevent scanner overheating.

Preprocessing. Before preprocessing, we identified global outlier time points by computing both the mean and the SD of values in each image for each slice. Mahalanobis distances for the matrix of mean values (one per slice) $\times$ functional volumes were computed, and images with a value $>3$ SDs were considered outliers. The same procedure was used for SD values. Outlier time points were modeled as indicator vectors during subject-level estimation. Functional images were then slice-acquisitiontiming and motion corrected using FSL (FMRIB's Software Library; http://www.fmrib.ox.ac.uk/fsl/). We incorporated a high-pass filter cutoff of $180 \mathrm{~s}$ into the general linear model (GLM) analysis.
Structural T1-weighted images were coregistered to the first functional image for each subject using an iterative procedure of automated registration using mutual information coregistration in SPM5 (Wellcome Trust Centre for Neuroimaging, London, UK) and manual adjustment of the automated algorithm's starting point until the automated procedure provided satisfactory alignment. Data were normalized to a standard MNI template (avg152T1.img) using the "unified segmentation" procedure of SPM5 (Ashburner and Friston, 2005), resampled to $2 \times 2 \times 2$ $\mathrm{mm}$ voxels, and smoothed with an $8 \mathrm{~mm}$-FWHM Gaussian smoothing kernel.

\section{FMRI analysis}

Pain-processing network localizer. Pain-processing regions were localized by a mega-analytic approach that assessed intensity processing across four separate experiments (total $n=93$ ) that contrasted high (level 8) versus low (level 2) stimulation using the same methods as in the study by Atlas et al. (2010). We performed nonmetric multidimensional scaling (NMDS) to identify networks of regions that clustered together across these datasets. Seven networks were identified. We identified anatomical boundaries within each network, based on the LONI Probabilistic Brain Atlas (Shattuck et al., 2008). Thirteen a priori regions of interest (ROIs) were defined based on membership in the pain-processing network (PPN), with boundaries defined based on voxel membership within both the same functional network and the same anatomical region of interest (see Fig. 4). 
Hemodynamic response assessment. To ensure that remifentanil did not affect the shape of the BOLD response itself, we extracted filtered time series data from each of the 13 PPN ROIs and used the Inverse Logit model (Lindquist and Wager, 2007; Lindquist et al., 2009) to estimate the noxious stimulus-evoked HRF as a function of drug concentration (Low, Medium, or High) and temperature (Hot vs Warm) for each subject. We did not observe significant differences in time-to-peak or width of the response as a function of expectancy, drug level, or temperature. This supported using the standard SPM hemodynamic response function in analysis. However, as expected based on previous work (Apkarian et al., 1999), we found evidence for a prolonged response to noxious heat (estimated at $14 \mathrm{~s}$ ), and thus used a $14 \mathrm{~s}$ duration epoch in GLM analyses.

Subject-level general linear model. First-level GLM analyses in SPM5 modeled epochs related to Heat, Pain Anticipation, and Pain Rating (activation during the 4-6 s rating slide presentation). The BOLD undershoot was not modeled to minimize collinearity between adjacent periods. Separate regressors were included for each of the following conditions: High Pain Open, High Pain Hidden, Low Pain Open, and Low Pain Hidden. We included parametric regressors for each of these conditions to model Drug effects (Büchel and Friston, 1997). The Drug modulator provided an estimate of pain modulation that paralleled the time course of predicted drug concentration (Drug effects; Fig. $2 \mathrm{~B}$, orange) separately under Open and Hidden contexts, allowing us to test the Drug $\times$ Context (Open - Hidden) interaction. We also tested for two kinds of expectancy effects that occurred with a different time course from brain drug concentration. First, we included an additional parametric modulator ("Infusion period orthogonalized") that estimated activity uniquely attributable to Instruction effects (Fig. $2 B$, purple). Regions affected by Instruction-related expectancies would show (Open - Hidden) differences in this time course. In a second model, we tested for Correlates of expectancy-related pain relief (Open - Hidden) differences in brain activity parametrically modulated by the time course of behavioral pain relief. We used pain reports on high intensity trials, smoothed within-subjects so that the effects of aberrant trials and withinrun habituation were minimized (Gaussian filter, FWHM = 5). A single parametric regressor was created that reflected the average (Open Hidden) difference in pain on each trial (i.e., the difference between the curves shown in Fig. 2C). To identify regions that were specifically related to expectancy effects on pain, we tested for voxels that showed reduced activity with this time course for Open versus Hidden administration.

Drug $\times$ Context interactions would imply that drug effects on painrelated brain responses differ as a function of expectations. Instructionrelated expectancy effects would demonstrate expectancy effects on brain activity dissociable from drug effects in time and/or brain location. Correlates of expectancy-related pain relief would demonstrate that expectations influence pain report-related processes, whether or not they interact with remifentanil.

We were most interested in whether these factors affected responses to high intensity noxious stimulation. Previous studies have shown placebo effects on painful but not innocuous stimuli (Wager et al., 2004, 2007a), and a number of studies have focused on placebo responses during painful stimulation alone (Lieberman et al., 2004; Price et al., 2007; Craggs et al., 2008; Eippert et al., 2009; Schweinhardt et al., 2009; Watson et al., 2009). However, we acknowledge that not all authors who have tested graded painful stimuli have found placebo effects specific to pain (Kong et al., 2006), and anticipatory responses may well be part of a more general mechanism that does not only affect nociception.

Group analysis. Group statistics were estimated using robust regression (Wager et al., 2005), including covariates for maximum absolute drug concentration (based on dose, age, weight, height, and gender) and order (Open first vs Hidden first).

ROI-wise results were analyzed by extracting regression coefficients and contrast values for each voxel within each PPN ROI, and averaging across voxels. We used robust $t$ tests to test whether estimates were significant across the group. Because PPN ROIs were specified a priori and involved tests on averages across voxels, we used a threshold of $p<0.05$.

Voxelwise tests were used to corroborate ROI-wise results and to examine effects on prefrontal and limbic regions. Results are reported at $p<0.001$ uncorrected, the most commonly reported threshold for fMRI
Table 1. Balanced placebo design results

\begin{tabular}{|c|c|c|c|c|}
\hline & \multicolumn{2}{|c|}{ No remifentanil administration } & \multicolumn{2}{|c|}{ Remifentanil administration } \\
\hline & Control & Placebo & Hidden & Open \\
\hline Average pain & 4.1021 & 3.6364 & 3.6993 & 3.4372 \\
\hline
\end{tabular}

(Wager et al., 2007b), with a cluster extent threshold of three voxels and a requirement that significant voxels be contiguous with voxels at uncorrected thresholds of $p<0.005$ and $p<0.01$.

\section{Results \\ Behavioral experiment results: additive effects on reported pain}

The balanced placebo design crossed drug administration with knowledge that the drug is being delivered in a $2 \times 2$ factorial design (Fig. 1), allowing us to test for main effects of Drug, main effects of Expectancy, and Expectancy $\times$ Drug interactions on pain reports evoked by noxious thermal stimulation (see Materials and Methods). Participants expected pain relief with remifentanil (pretask-expected efficacy: $M=6.46, \mathrm{SD}=1.80$; confidence: $M=6.70, \mathrm{SD}=1.56$ ).

We were most interested in assessing the within-subjects effects of Drug and Expectancy, and testing whether they interact or influence pain in an additive manner. Average pain reports as a function of condition are presented in Table 1. A significant Drug effect on pain $\left(t_{(13)}=-4.10, p<0.01\right)$ indicated that participants reported less pain with remifentanil administration, regardless of expectancy. A significant main effect of Expectancy $\left.t_{(13)}=-2.29, p<0.05\right)$ indicated that participants reported less pain when they believed they were receiving the drug (Open and Placebo conditions) than when they believed they were receiving no drug (Hidden and Control conditions). We found no evidence for Drug $\times$ Expectancy interactions $\left(t_{(13)}=-0.04, p>\right.$ $0.90)$. Thus remifentanil and expectancy both reduced pain in an additive manner, without interactions.

Our model also tested the within-subjects effects of Temperature and Run. There was a robust effect of Temperature $\left(t_{(13)}=\right.$ $28.21, p<0.0001)$, such that subjects reported greater pain with higher intensity stimulation, and a main effect of Run $\left(t_{(930)}=\right.$ $-2.44, p<0.05$ ), such that participants reported less pain across the session, likely due to habituation. We observed a significant Drug $\times$ Temperature interaction $\left(t_{(930)}=-2.36, p<0.05\right)$, such that drug effects were stronger under high pain. There was no evidence for Expectancy $\times$ Drug interactions $\left(t_{(930)}=0.01, p>\right.$ $0.9)$, or Expectancy $\times$ Temperature interactions $\left(t_{(930)}=-1.12\right.$, $p>0.2$ ). Finally, our multilevel analysis also modeled individual differences in absolute remifentanil concentration. Subjects who received higher overall levels of remifentanil actually reported more pain on average $\left(t_{(13)}=2.88, p<0.01\right)$; we believe this is likely to be due to the factors that lead to different absorption rates of the drug, including gender and weight (Minto et al., 1997b), as the maximum level of remifentanil was greater for females at the fixed dose we used in this experiment. In the fMRI experiment, where doses were individually selected for each participant, there was no such relationship between pain ratings and maximum drug concentration.

Retrospective ratings of average pain intensity and unpleasantness were collected as soon as the infusion period terminated on each run (i.e., at the start of the washout period), at peak remifentanil concentration. We found that remifentanil decreased overall ratings of intensity $\left(t_{(12)}=-3.27, p<0.01\right)$ and unpleasantness $\left(t_{(12)}=-4.37, p<0.001\right)$ and increased ratings of pleasantness of noxious stimulation $\left(t_{(9)}=2.82, p<0.05\right.$ ), 
regardless of expectancy. Expectancy did not affect ratings of pleasantness or unpleasantness (all $p$ values $>0.2$ ) and led to marginal effects on pain intensity ratings $\left(t_{(12)}=-1.47\right.$, twotailed $p=0.17$ ). There were no interactions between expectancy and drug administration on any of the summary measures (all $p$ values $>0.2)$.

\section{FMRI experiment: dissociable effects of drug and expectancy on pain-related brain responses \\ Behavioral results}

Additive effects of Drug and (Open - Hidden) Context. We examined expectancy ratings as a manipulation check. Participants expected pain relief with remifentanil, both before and after the dosing procedure (predosing-expected efficacy: $M=7.29$, $\mathrm{SD}=1.70$; postdosing-expected efficacy: $M=7.56, \mathrm{SD}=1.69$ ). While there was no difference in expected analgesic efficacy, the dosing procedure increased confidence in participants' expectations (predosing confidence: $M=6.31, \mathrm{SD}=2.24$; postdosing confidence: $M=7.78, \mathrm{SD}=1.58$ ). Thus, participants had confident expectations for pain relief before the imaging portion of the experiment.

Analyses of pain reports replicated findings from the behavioral experiment. Again, there were significant Drug effects (Drug effect orthogonalized: $t_{(16)}=-3.29, p<0.001$; Infusion period orthogonalized: $t_{(16)}=-3.43, p<0.001$ ), indicating pain reduction with higher drug concentration, and significant Context effects [(Open - Hidden); both models: $t_{(16)}=-1.70$, onetailed $p<0.05]$, indicating lower pain with Open versus Hidden administration. Pain was also influenced by Instruction-related expectancies, or effects that paralleled the time course of information about the drug infusion during Open administration, as we found a significant Infusion period $\times$ Context interaction in both models (Drug effect orthogonalized: $t_{(16)}=-2.01, p<$ 0.05; Infusion period orthogonalized: $t_{(16)}=-2.19, p<0.05$ ). Post hoc tests showed that this was driven by pain reduction during the infusion period in Open administration (both models: $t_{(16)}=-2.22$, one-tailed $\left.p<0.05\right)$, indicating that expectancy reduced pain after the start of open administration in advance of the rise in drug concentration, as illustrated in Figure 2C. The Infusion period was not associated with changes in pain overall (i.e., across Open and Hidden) in either model $(p>0.3)$. We found strong main effects of Intensity (both models: $t_{(16)}=12.10$, $p<0.001$ ) and linear effects of Trial (both models: $t_{(16)}=-7.33$, $p<0.001$ ), indicating that participants reported more pain with high intensity stimulation and that habituation led to a reduction in pain within each block, although we found no evidence of habituation across sessions (all $p$ values $>0.7$ ). Finally, there was no evidence of any Drug $\times$ Context interaction (all $p$ values $>0.3$ ), nor were there any three-way interactions between Intensity, Drug, and Context (all $p$ values $>0.5$ ) or Intensity, Context, and Infusion period (all $p$ values $>0.7$ ). None of these effects were moderated by maximum drug concentration or order (all $p$ values $>0.5$ ), and there was no relationship between reported pain and maximum drug concentration (both models: $p>0.7$ ) or order (both models: $p>0.15$ ).

We used the same approach to test effects within high intensity trials. Pain reports on high intensity trials were reduced during Open administration, relative to Hidden administration (both models: $t_{(16)}=-2.27, p<0.01$ ), and increases in remifentanil concentration were associated with reduced pain (Drug effect orthogonalized: $t_{(16)}=-3.82, p<0.001$; Infusion period orthogonalized: $\left.t_{(16)}=-3.92, p<0.001\right)$. We found strong effects of Trial within each skin site (both models: $t_{(16)}=-6.46$, $p<0.001$ ), but no evidence of habituation across the session (both models: $p>0.9$ ). While there was a marginally significant effect of Instruction-related expectancies (Run $\times$ Infusion period interaction) when this effect was modeled first (Drug effect orthogonalized: $t_{(16)}=-1.29$, one-tailed $p=0.059$ ), this effect was less apparent when drug effects were modeled first (Infusion period orthogonalized: $t_{(16)}=-1.28$, one-tailed $p=0.110$ ). Finally, neither model showed a difference in drug effects between Open and Hidden administration (all $p$ values $>0.4$ ).

Thus, in summary, the fMRI experiment replicated the results obtained in the behavioral experiment. We found additive effects of Expectancy (both Context effects and Instruction-related expectancies) and Drug, with no Drug $\times$ Expectancy interactions. Remifentanil also reduced pain reports more strongly during High intensity stimulation than during Low intensity stimulation in both studies.

\section{Drug effects on pain-processing regions without Drug $\times$ Context interactions}

To test for influences on nociceptive processing, we conducted tests within a priori PPN ROIs (see Materials and Methods). We expected drug and expectancy-induced decreases in PPN ROIs. We also tested for drug- and expectancy-induced increases in prefrontal cortex (PFC) and limbic regions, as previous studies of expectancy effects on pain have consistently shown expectancyinduced increases in left dorsolateral prefrontal cortex (DLPFC), rostral anterior cingulate (rACC), and the periaqueductal gray (PAG) (Wager et al., 2004; Bingel et al., 2006; Craggs et al., 2007; Eippert et al., 2009; Atlas et al., 2010; Wager and Fields, 2012).

Across Open and Hidden administration, significant negative Drug effects in most PPN ROIs indicated that remifentanil reduced activity during painful stimulation in pain processingrelated areas. These included dorsal and rostrodorsal anterior cingulate cortex (dACC and rdACC), right middle insula, bilateral anterior insula, midbrain, and thalamus (all $p<0.05$; Figs. $3 A, 4$ ). Voxelwise results corroborated these findings (Fig. $3 B$, Table 2) and additionally showed drug-induced reductions during pain in the striatum (bilateral caudate and left putamen), right amygdala, medial PFC, and dorsomedial PFC (DMPFC; middle frontal gyrus), and drug-induced increases in medial orbitofrontal cortex (OFC) and temporal and occipital regions (Fig. $3 B$, Table 2). Medial OFC is generally deactivated by pain, suggesting that remifentanil reduced pain-induced deactivation.

Similar, strong drug effects were observed in each of the Open and Hidden conditions separately (Fig. 3C,D), and therefore we observed little evidence for drug $\times$ expectancy interactions. ROI analyses showed no significant Drug $\times$ Context (Open - Hidden) effects in any region tested, despite good sensitivity in these regions to both temperature (High - Low pain) and drug concentration (Fig. 4). Voxelwise results showed similarly weak effects. Significant overadditive interactions were found in two PPN regions, right middle insula and medial cerebellum (Fig. 3E, Table 3). However, both regions were small, and examination of the fitted responses suggested that the effects were not driven by a larger modulatory effect in Open administration, but rather a difference in the timing of modulation (earlier in Hidden). We also observed significant interactions of a different type in several regions outside the PPN: right DLPFC and DMPFC (both in the middle frontal gyrus), left precentral gyrus, left amgydala, and right inferior parietal lobule (Table 3). Remifentanil caused larger decreases in these regions during Hidden administration, due largely to high responses off drug in the Hidden condition. The interpretation of this type of interaction is not clear; it is possibly 


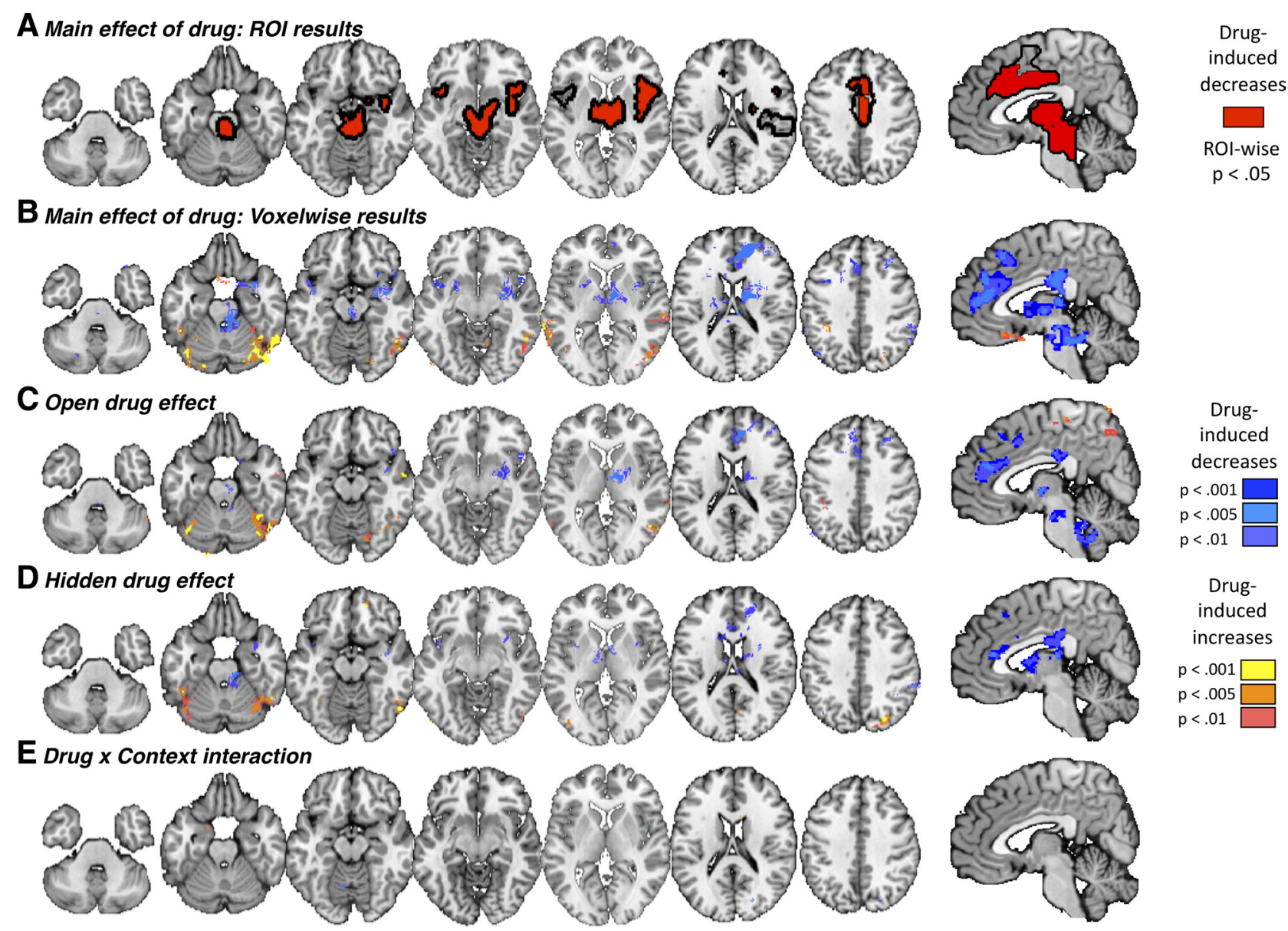

Figure 3. Drug effects on PPN responses. Increases in the brain concentration of remifentanil were associated with reductions in pain-evoked responses throughout the PPN, evident in both ROI (red, top row) and voxelwise analyses (second row). Drug effects were similar during both Open administration (third row) and Hidden administration (fourth row), leading to no meaningful Drug $X$ Context interactions (bottom row).

consistent with anxiety-related responses in the Hidden condition blocked by remifentanil, but it is not consistent with drug $X$ expectancy interactions on pain-related signals.

(Open - Hidden) expectancy effects with a different time course from Drug effects

Our analyses of Drug effects revealed that remifentanil effects on PPN heat-evoked responses were largely identical regardless of expectancy. However, our behavioral analyses revealed that pain reports were indeed influenced by both remifentanil and expectancy. We used two approaches to directly assess the mechanisms by which expectancies modulate pain in the context of opiate treatment.

First, we examined Instruction-related expectancy effects, (Open - Hidden) differences during the infusion period that thus began earlier and resolved earlier than brain drug concentration. Instruction-related expectancy effects were not found in ROI analyses of any PPN regions. Voxelwise analyses yielded instruction-related reductions in left dorsal posterior insula (near, but outside, the PPN) and in several limbic regions associated with negative affect, including left amygdala, parahippocampal gyrus, ventral striatum, and an area consistent with the bed nucleus of the stria terminalis (Fig. 5A, Table 4). These areas have been associated with pain-related affect in several studies (Becerra et al., 2001; Ploghaus et al., 2001; Bingel et al., 2002). Instruction-related increases were found in left DLPFC, in both the pars triangularis of the inferior frontal gyrus (BA45) and superior frontal gyrus, consistent with findings in studies of placebo analgesia (Wager et al., 2004, 2011; Craggs et al., 2007; Wager and Fields, 2012). Thus, the time course of instructions during open drug administration was accompanied by changes in limbic/PFC/striatal regions, and revealed brain effects of expectations that were different in time and location from the effects of remifentanil.

The instruction period provided one guide as to when expectancy effects might occur, but the strongest Open versus Hidden expectancy effects on the PPN would be expected to follow the precise time course of (Open - Hidden) effects on pain reports, which rose during drug infusion as did brain drug concentration, but with a different temporal profile ( $r=0.26$ with drug concentration; Fig. 2C). This would isolate expectancy effects on the trials when there was a behavioral effect of expectancy. Correlates of expectancy-related pain relief were found in PPN regions, including bilateral somatosensory cortex (SII), bilateral thalamus, right anterior insula, and presupplementary motor area (preSMA; Fig. 5B). In each of these regions, reduced responses to noxious input were found for Open relative to Hidden administration, with a time course across trials concordant with expectancy effects on reported pain. These findings replicate the essential findings of Bingel et al. (2011) regarding expectancy effects during remifentanil administration and other studies of placebo analgesia (Wager et al., 2004; Price et al., 2007; Watson et al., 2009). We also observed report-related changes outside of the 


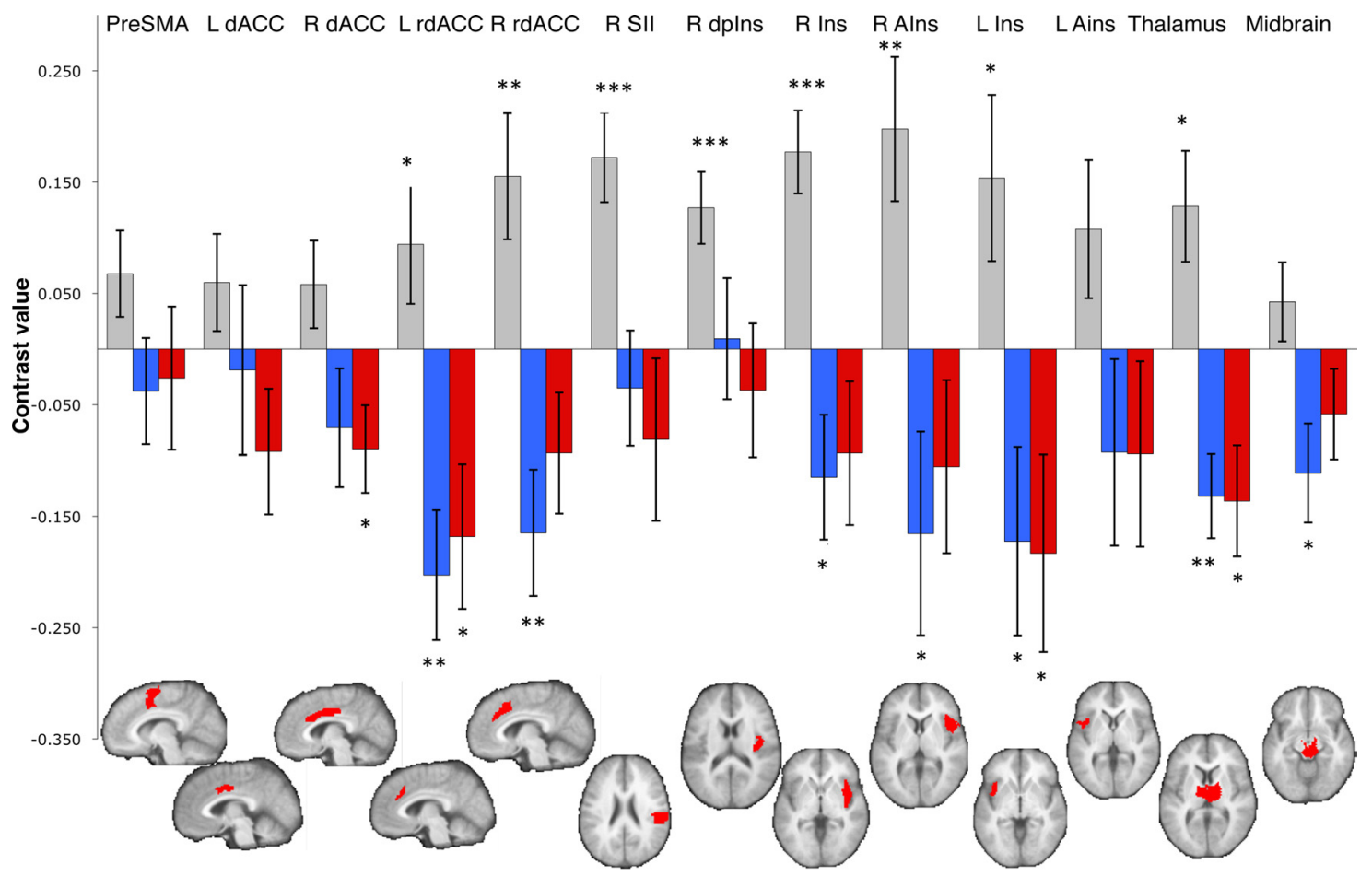

Figure 4. Region of interest results. We defined 13 pain-processing network ROls, using independent datasets, and averaged across voxels within each ROI. We tested whether each was modulated by remifentanil during Open administration (blue bars) and Hidden administration (red bars). While most regions showed significant differences between high and low intensity stimulation (gray bars), estimated Drug effects did not differ between Open and Hidden administration in any ROls. We tested the following ROls: pre-SMA, bilateral dACC, rdACC, secondary somatosensory cortex (SII), right dorsal posterior insula (R dpIns), bilateral insula (Ins), bilateral anterior insula (Alns), thalamus, and midbrain surrounding the periacqueductal gray. One-tailed ${ }^{*} p<0.05 ; *{ }^{*} p<0.01 ; * * * 00.001$.

Table 2. Remifentanil-induced changes during high intensity stimulation

\begin{tabular}{|c|c|c|c|c|c|c|}
\hline Region & $x$ & $y$ & $z$ & $\begin{array}{l}\text { No. of } \\
\text { voxels }\end{array}$ & $\begin{array}{l}\text { Volume } \\
\left(\mathrm{mm}^{3}\right)\end{array}$ & $\begin{array}{l}-\log (\text { Min } \\
p \text { value })\end{array}$ \\
\hline \multicolumn{7}{|l|}{ Drug-induced increases } \\
\hline Left fusiform gyrus & -40 & -68 & $8-18$ & 990 & 7920 & 11.77 \\
\hline Left cerebellum VI & -36 & -34 & $4-30$ & 29 & 232 & 8.89 \\
\hline Right inferior occipital gyrus & 44 & -64 & $4-14$ & 2426 & 19408 & 13.84 \\
\hline Left rectal gyrus & -2 & 18 & $8-20$ & 118 & 944 & 7.29 \\
\hline Right lingual gyrus (BA18) & 12 & -56 & $6-4$ & 52 & 416 & 7.6 \\
\hline Right superior temporal gyrus & 60 & -28 & 4 & 450 & 3600 & 10.17 \\
\hline Left middle temporal gyrus & -60 & -42 & 4 & 404 & 3232 & 10.47 \\
\hline Left middle temporal gyrus & -44 & -64 & 6 & 36 & 288 & 10.4 \\
\hline Right superior occipital gyrus & 22 & -78 & $8 \quad 36$ & 233 & 1864 & 9.5 \\
\hline Left inferior parietal lobule & -36 & -40 & $0 \quad 42$ & 93 & 744 & 7.54 \\
\hline Left postcentral gyrus (BA2) & -42 & -40 & $0 \quad 64$ & 319 & 2552 & 10.29 \\
\hline \multicolumn{7}{|l|}{ Drug-induced decreases } \\
\hline Left cerebellum crus 1 & -20 & -70 & $0-34$ & 135 & 1080 & 12.08 \\
\hline $\begin{array}{l}\text { Right ventral striatum, contiguous with } \\
\text { right anterior insula, rdACC, bilateral } \\
\text { thalamus, right amygdala, preSMA, } \\
\text { DMPFC, PAG, pons }\end{array}$ & 6 & 8 & $8 \quad 12$ & 8471 & 67768 & 16.35 \\
\hline Left insula lobe & -42 & 4 & $4-8$ & 206 & 1648 & 8.79 \\
\hline Right inferior occipital gyrus (BA17) & 30 & -98 & $8-8$ & 33 & 264 & 8.52 \\
\hline Right supramarginal gyrus & 56 & -40 & $0 \quad 38$ & 609 & 4872 & 8.76 \\
\hline Left angular gyrus & -38 & $3-72$ & 248 & 177 & 1416 & 11.73 \\
\hline Left supramarginal gyrus & -60 & -48 & $8 \quad 44$ & 295 & 2360 & 13.46 \\
\hline Right middle frontal gyrus & 34 & 34 & $4 \quad 40$ & 132 & 1056 & 8.27 \\
\hline
\end{tabular}

PPN; pain reduction during Open administration was associated with decreased responses during pain in cerebellum, bilateral amygdala, and right DMPFC and increases in medial OFC, left hippocampus, bilateral middle temporal gyrus, left inferior parietal lobule and subgenual ACC (Fig. 5B, Table 5). Thus, the Open
Table 3. Differences in remifentanil effects during Open and Hidden administration

\begin{tabular}{|c|c|c|c|c|c|c|}
\hline Anatomy toolbox & $x$ & $y$ & $Z$ & $\begin{array}{l}\text { No. of } \\
\text { voxels }\end{array}$ & $\begin{array}{l}\text { Volume } \\
\left(\mathrm{mm}^{3}\right)\end{array}$ & $\begin{array}{l}-\log (\text { Min. } \\
p \text { value) }\end{array}$ \\
\hline \multicolumn{7}{|l|}{ Open remifentanil > Hidden remifentanil } \\
\hline Left parahippocampal gyrus/amygdala & -16 & 4 & -20 & 23 & 184 & 7.79 \\
\hline Right middle frontal gyrus (DMPFC) & 26 & 56 & 26 & 21 & 168 & 9.25 \\
\hline Left supramarginal gyrus & -48 & -12 & 58 & 19 & 152 & 7.75 \\
\hline Right middle frontal gyrus & 38 & 24 & 54 & 17 & 136 & 10.03 \\
\hline Right inferior parietal lobule & 58 & -38 & 54 & 15 & 120 & 7.91 \\
\hline \multicolumn{7}{|l|}{ Hidden remifentanil $>0$ 0pen remifentanil } \\
\hline Left cerebellum IV-V & -8 & -60 & -14 & 37 & 296 & 9.05 \\
\hline Right insula lobe & 46 & 0 & 4 & 18 & 144 & 7.94 \\
\hline Right calcarine gyrus (BA17) & 22 & -74 & 12 & 24 & 192 & 9.79 \\
\hline
\end{tabular}

(vs Hidden) Context did produce reduced pain-related responses in PPN regions, as did remifentanil, but with a different time course across trials. As before, the effects were dissociable in time, and inconsistent with interactions between drugs and expectations.

\section{Discussion}

Prior research suggests that placebo and remifentanil analgesia share common mechanisms of action. Both target $\mu$-opioid receptors (Levine et al., 1978; Zubieta et al., 2005; Wager et al., 2007a; Eippert et al., 2009), and they are associated with increases in overlapping brain regions (PAG and rACC in particular) during pain (Petrovic et al., 2002). These common mechanisms could lead to competition for receptor availability or neural synergies, leading to underadditive or overadditive interactions, respectively. Both types of interactions have been found in the past, in treatments as diverse as naproxen for cancer pain (Bergmann 
A Instruction-related expectancy effects

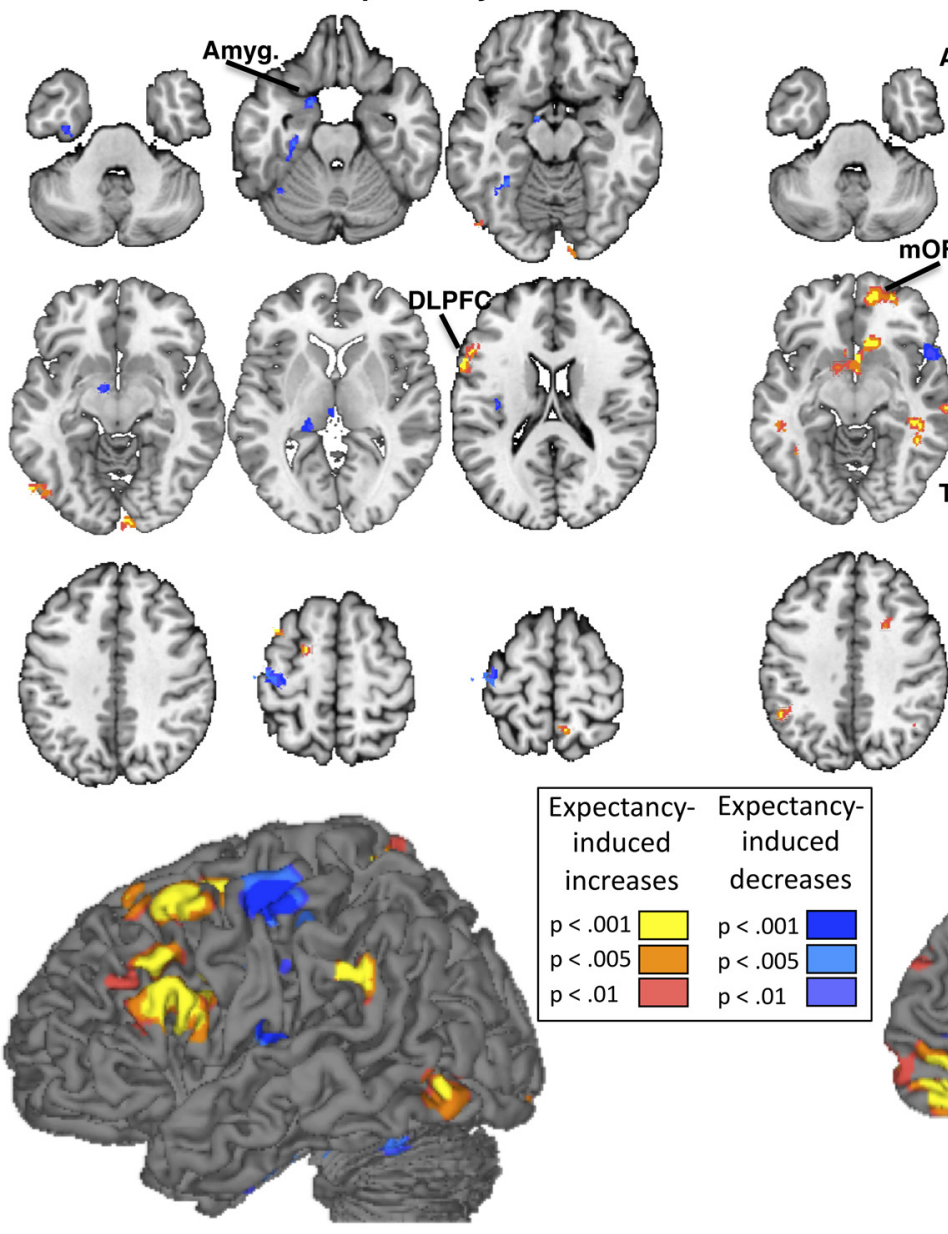

B Correlates of expectancy-related pain relief
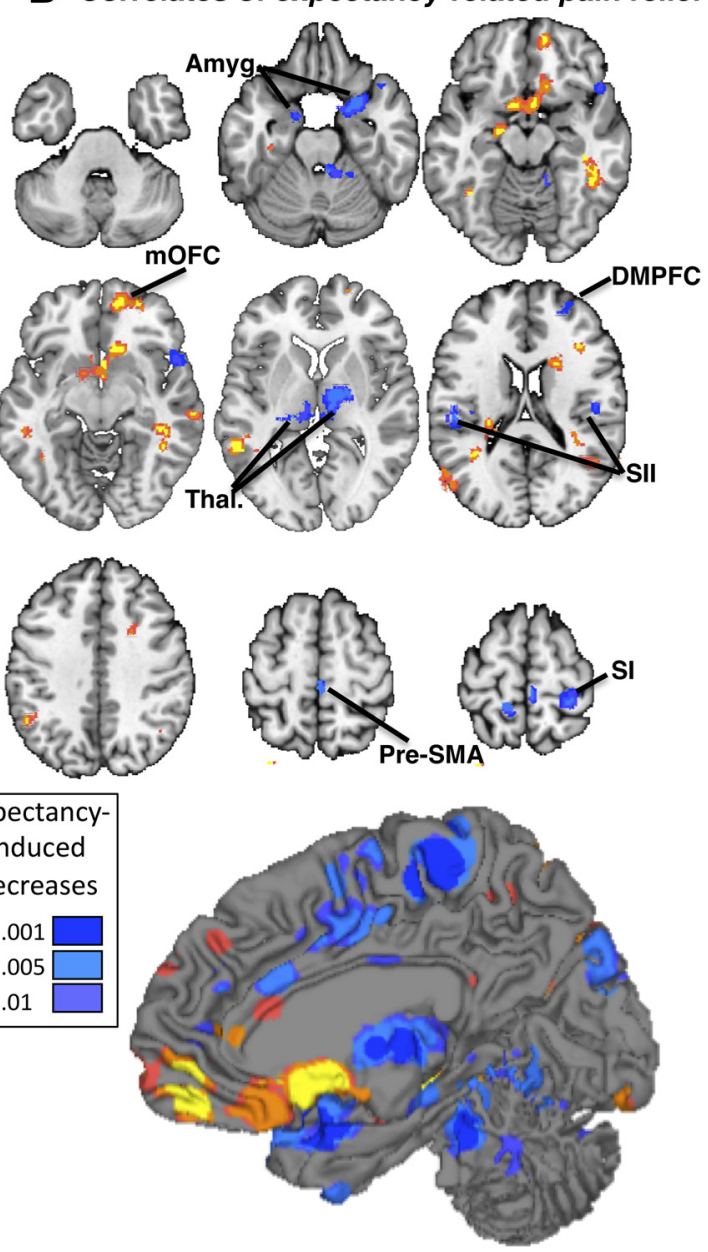

Figure 5. Expectancy effects during drug treatment. $\boldsymbol{A}$, Information about drug delivery during Open administration was accompanied by increases in left DLPFC, relative to the same period during Hidden administration ("Instruction-related expectancy effects"). We also observed expectancy-related decreases in the left amygdala (Amyg.). $\boldsymbol{B}$, A number of brain regions showed differences in activation that tracked within-subjects expectancy effects on pain reports over time ("Correlates of expectancy-related pain relief"). In particular, we observed report-related changes within the medial orbitofrontal cortex (mOFC), as well as several PPN regions, including right primary somatosensory cortex (SI), bilateral SII, bilateral thalamus, and pre-SMA. dACC showed significant expectancy-related reductions at a more liberal threshold, $p<0.005$.

et al., 1994), epinephrine (Penick and Fisher, 1965), caffeine (Flaten and Blumenthal, 1999), proglumide (Benedetti et al., 1995), acupuncture treatment (Kong et al., 2009a,b), and several others (Kleijnen et al., 1994). If drug effects differ as a function of belief, this would undermine the assumptions underlying the standard clinical trial. However, the set of studies we present here indicates that, when combined, opiate drug effects and expectancy effects on brain activity and behavior are in fact additive and dissociable, with effects on different brain regions and at different times.

In this paper, we tested whether drug effects depend on belief by manipulating both remifentanil and expectation and directly testing for interactions. Across two studies, we found support for additive, independent effects of expectancy and remifentanil on pain and pain-related fMRI activity. The behavioral experiment used a balanced placebo design, which revealed that expectations (induced by instructions about remifentanil delivery) reduced pain during active opiate administration, consistent with previous findings (Bingel et al., 2011). Remifentanil also reduced pain. However, testing drug and expectancy in a factorial design revealed effects of belief that were additive with drug effects, consistent with the assumptions of randomized clinical trials.
In the fMRI experiment, in place of the balanced placebo design, we used pharmacokinetic model-based estimates of drug concentration across time (Minto et al., 1997a,b; Wise et al., 2002, 2004) to test interactions between remifentanil and expectancies manipulated by Open versus Hidden administration context and instructions. Pain reports were affected by both remifentanil and information about drug delivery, but druginduced pain reduction was the same in both Open and Hidden conditions. Thus, the results replicated the additive effects of the behavioral experiment, illustrating that the same conclusions can be made even when the time course of expectancy versus drug effects is used to isolate effects, rather than the traditional balanced placebo design (although we note that the balanced placebo approach might have more explanatory power in some cases due to the factorial design). Additivity has been used in pain and placebo research (Gracely et al., 1983; Buhle et al., 2012) and other areas (Sternberg, 1969) as evidence for separable processing. For example, Gracely et al. (1983) found that placebo and the opiate antagonist naloxone had additive effects on dental pain, suggesting opioid-independent placebo effects.

fMRI results corroborated the additive effects on pain reports. Remifentanil and expectancy modulated PPN responses during 
Table 4. Expectancy-related changes during high intensity stimulation: Instruction effects

\begin{tabular}{|c|c|c|c|c|c|c|}
\hline Region & $x$ & $y$ & $z$ & $\begin{array}{l}\text { No. of } \\
\text { voxels }\end{array}$ & $\begin{array}{l}\text { Volume } \\
\left(\mathrm{mm}^{3}\right)\end{array}$ & $\begin{array}{l}-\log (\text { Min. } \\
p \text { value })\end{array}$ \\
\hline \multicolumn{7}{|l|}{$\begin{array}{l}\text { Expectancy-induced increases } \\
\text { (Open }>\text { Hidden) }\end{array}$} \\
\hline Right lingual gyrus (BA17) & 10 & -96 & -8 & 47 & 376 & 8.15 \\
\hline Left inferior occipital gyrus & -52 & -72 & -6 & 57 & 456 & 8.36 \\
\hline $\begin{array}{l}\text { Left inferior frontal gyrus } p \text {. triangularis } \\
\text { (BA45; DLPFC) }\end{array}$ & -54 & 18 & 26 & 433 & 3464 & 10.35 \\
\hline Left precuneus & -4 & -60 & 50 & 10 & 80 & 9.02 \\
\hline Left middle frontal gyrus (DLPFC) & -44 & 14 & 58 & 105 & 840 & 10.51 \\
\hline Left superior frontal gyrus & -22 & 0 & 58 & 40 & 320 & 9.63 \\
\hline Right precuneus & 10 & -52 & 68 & 32 & 256 & 9.05 \\
\hline \multicolumn{7}{|l|}{$\begin{array}{l}\text { Expectancy-induced decreases } \\
\qquad \text { (Hidden }>0 \text { 0pen })\end{array}$} \\
\hline Left parahippocampal gyrus & -28 & -16 & -28 & 90 & 720 & 8.29 \\
\hline Left fusiform gyrus & -34 & -48 & -16 & 85 & 680 & 10.37 \\
\hline Left amygdala & -18 & 4 & -24 & 37 & 296 & 9.57 \\
\hline Internal globus pallidus & -10 & -4 & -10 & 21 & 168 & 8.78 \\
\hline Left caudate nucleus & -10 & 10 & -2 & 25 & 200 & 7.73 \\
\hline Left posterior thalamus & -12 & -28 & 10 & 165 & 1320 & 9.99 \\
\hline $\begin{array}{l}\text { Left rolandic operculum (dorsal posterior } \\
\text { insula) }\end{array}$ & -38 & -18 & 18 & 102 & 816 & 10.89 \\
\hline Left precentral gyrus (BA6) & -42 & -18 & 58 & 224 & 1792 & 11.14 \\
\hline
\end{tabular}

pain and other brain processes in dissociable ways. Remifentanilinduced reductions in PPN regions were widespread, indicating reduced nociceptive/pain-related activity. However, we did not find substantial evidence for differences in drug effects with high versus low expectations of analgesia, as manipulated by Open versus Hidden administration context, in either ROI analyses or voxelwise maps. Rather, expectancy had more limited effects on PPN, with a time course that paralleled expectancy effects on behavioral reports and began when the drug infusion started, before drug concentration in the brain reached peak levels. Thus, expectancy and drug effects on PPN regions were dissociable in that they occurred at different times during the course of the experiment.

Drug and expectancy effects were also dissociable in the sense that they primarily influenced different brain regions. Expectations associated with information about drug delivery reduced activity in limbic areas outside of the typical PPN regionschanges that appeared to be shared with drug effects-and increased prefrontal activity, which was not shared with drug effects. Both effects of expectancy have been found in other studies. For example, we recently found that both anticipatory placebo-induced increases in prefrontal cortex and reductions during pain in ventral striatum and other limbic areas predicted the magnitude of placebo analgesia across individuals (Wager et al., 2011).

Our results challenge the notion that expectancy effects interact synergistically with opioidergic drugs, despite the fact that expectancy effects elicited in similar opiate drug-conditioning paradigms have been shown to be opioid-dependent (Amanzio et al., 2001). Thus, rather than expectancy "doubling the analgesic benefit of remifentanil” (Bingel et al., 2011), as has recently been suggested, we offer the alternative interpretation that expectancy operates alongside, but independent of, remifentanil.

An additional benefit of the present study is that we used an ecological method of eliciting expectancies. Previous studies of expectancy effects during drug administration (Bingel et al., 2011) and placebo analgesia used conditioning manipulations, in
Table 5. Expectancy-related differences in pain report-related responses during remifentanil administration

\begin{tabular}{|c|c|c|c|c|c|c|}
\hline Regions & $x$ & $y$ & $z$ & $\begin{array}{l}\text { No. of } \\
\text { voxels }\end{array}$ & $\begin{array}{l}\text { f Volume } \\
s\left(\mathrm{~mm}^{3}\right)\end{array}$ & $\begin{array}{l}e-\log (\text { Min } \\
p \text { value })\end{array}$ \\
\hline \multicolumn{7}{|l|}{$\begin{array}{l}\text { Expectancy-related increases associated with } \\
\text { pain relief (Open }>\text { Hidden) }\end{array}$} \\
\hline Left hippocampus (CA) & -34 & $4-22$ & -18 & 22 & 176 & 8.77 \\
\hline Inferior temporal gyrus & 44 & $4-38$ & -10 & 239 & 1912 & 13.58 \\
\hline Right midorbital gyrus & 16 & $6 \quad 58$ & -6 & 398 & 3184 & 13.85 \\
\hline Left amygdala & -20 & -8 & -12 & 53 & 424 & 8.16 \\
\hline Right subgenual anterior cingulate cortex & 4 & $4 \quad 14$ & -10 & 378 & 3024 & 11.03 \\
\hline Left middle temporal gyrus & -58 & $8-50$ & & 344 & 2752 & 10.65 \\
\hline Right middle temporal gyrus & 66 & $6-26$ & -4 & 157 & 1256 & 10.81 \\
\hline Right middle temporal gyrus & 52 & $2-56$ & 16 & 290 & 2320 & 8.02 \\
\hline $\begin{array}{l}\text { Right inferior frontal gyrus, pars } \\
\text { opercularis }\end{array}$ & 38 & $8 \quad 26$ & 20 & 18 & 144 & 10.12 \\
\hline Right superior occipital gyrus & 28 & $8-66$ & 30 & 166 & 1328 & 14.47 \\
\hline Right angular gyrus & 46 & $6-60$ & 34 & 75 & 600 & 7.93 \\
\hline Left inferior parietal lobule & -48 & $8-50$ & 40 & 25 & 200 & 10.59 \\
\hline Left angular gyrus & -32 & $2-82$ & 48 & 28 & 224 & 8.91 \\
\hline \multicolumn{7}{|l|}{$\begin{array}{l}\text { Expectancy-related decreases associated with } \\
\text { pain relief (Hidden }>0 \text { pen) }\end{array}$} \\
\hline Left amygdale & -14 & 0 & -24 & 37 & 296 & 13.23 \\
\hline Right amygdale & 34 & $4 \quad 12$ & -22 & 372 & 2976 & 10.16 \\
\hline Right cerebellum III & 12 & $2-40$ & -22 & 119 & 952 & 9.26 \\
\hline Left thalamus & -12 & $2-20$ & & 237 & 1896 & 10.32 \\
\hline Right thalamus & 12 & $2-14$ & & 350 & 2800 & 14.82 \\
\hline Left SII/Postcentral gyrus & -50 & $0-20$ & 18 & 82 & 656 & 10.02 \\
\hline Right middle frontal gyrus & 26 & $6 \quad 52$ & 22 & 95 & 760 & 8.85 \\
\hline Left dorsal posterior insula & -36 & $6-20$ & 18 & 14 & 112 & 10.19 \\
\hline Right dorsal posterior insula & 48 & $8-16$ & 24 & 64 & 512 & 8.43 \\
\hline Left S1/Postcentral Gyrus (BA3a) & -36 & $6-24$ & 46 & 43 & 344 & 9.94 \\
\hline Left superior parietal lobule & -26 & $6-68$ & 48 & 33 & 264 & 7.74 \\
\hline Right paracentral lobule (BA4a) & & $4-30$ & 64 & 72 & 576 & 11.74 \\
\hline Left precuneus (BA3a) & -12 & $2-42$ & 66 & 60 & 480 & 11.56 \\
\hline Right S1/Postcentral gyrus & 30 & $0-34$ & 66 & 148 & 1184 & 9.68 \\
\hline Left paracentral lobule (BA4a) & -8 & $8-40$ & 76 & 8 & 64 & 8.07 \\
\hline Right postcentral gyrus (BA4a) & 14 & $4-38$ & 76 & 6 & 48 & 8.43 \\
\hline
\end{tabular}

which drug/placebo administration was paired with reductions in actual stimulus intensity. The type of expectancies that are induced through procedures that lower stimulation are quite different from the effects of prior exposure to drug treatment (Kirsch et al., 2004), and participants' learning history strongly influences placebo analgesia (Colloca and Benedetti, 2009). Here, participants in the behavioral experiment had no prior experience with remifentanil, and fMRI experiment participants received various doses paired with high intensity stimulation during a fully Open label dosing procedure before the experimental session (see Materials and Methods). These approaches are likely to elicit the type of expectations observed in the clinic more closely than surreptitious procedures, as patient expectations generally stem from previous experiences with drug treatment or beliefs without prior experience.

Our findings have implications for clinical trials, for treatment, and for future research. They support the validity of the assumptions underlying RCTs for opiate drugs, while also illustrating that expectations and beliefs do influence patients' subjective experience and associated neural responses. Thus, optimal patient outcomes can be achieved by pairing medication with high expectation of relief. Naturally, interactions between psychological states and drugs may depend heavily on both the psychological state (e.g., anxiety might interact with opiate treatment) and the drug (e.g., other opiates, nonsteroidal antiinflammatory analgesics, or cannabinoids may interact with ex- 
pectations). Thus, this study represents an initial step in an important research program that tests for drug $\times$ expectancy interactions with different combinations of drug treatment and psychological contexts or interventions. Efforts toward testing drug $\times$ expectancy interactions have been made in several areas, including alcohol and drug research (Rohsenow and Marlatt, 1981; Volkow et al., 2003; Gundersen et al., 2008) and pain (Levine and Gordon, 1984; Kleijnen et al., 1994; Martin et al., 1994; Kong et al., 2009a,b). Incorporation of brain activity measures into this experimental framework has the potential to elucidate how drug effects may vary as a function of the endogenous state of the drug recipient, and thus to advance the goals of enhancing treatment effects in general and personalized medicine in particular. These efforts are all the more important when considering the brain mechanisms underlying clinically relevant phenomena, as pharmacological treatments often work on the same neural and neurochemical mechanisms as endogenous selfregulatory processes. Thus, we hope that this study will help serve as a launching point for testing for interactions between pharmacological and psychological processes in other domains.

As with any study, several considerations must be evaluated in adopting this approach for future studies or clinical trials. First, we used a low dose $(0.04 \mu \mathrm{g} / \mathrm{kg} / \mathrm{min})$ of remifentanil to avoid unblinding (awareness of whether the true drug was given or not based on side effects) in the Hidden condition. This dose was essentially identical to the dose applied in previous work (Bingel et al., 2011). It is possible that conclusions about additivity might be valid only for low doses. At higher doses, unblinding could reduce placebo effects and/or make the balanced placebo design impractical.

Partial unblinding is also a possibility in this study, though we do not believe it substantively affected our results. We selected doses for each person to produce analgesia while minimizing subjective awareness of side effects in the fMRI experiment, and participants' guesses about the true drug blocks were not better than chance in the behavioral experiment. If partial unblinding did occur, it would create an overadditive interaction (apparent synergy), while in fact we observed a nonsignificant trend toward under-additive interactions in both studies.

It remains unknown whether similar brain mechanisms of placebo effects and potential placebo-drug interactions would be observed if a different drug were used. As mentioned, placebo analgesia and remifentanil analgesia share many mechanisms; future research should examine whether and how expectancies interact with other drugs. Finally, testing the balanced placebo design necessarily involves some deception, and therefore may not be suitable for every type of clinical study.

\section{Notes}

Supplemental material for this article is available at http://wagerlab. colorado.edu, http://www.columbia.edu/ lya2103. Supplemental material includes details on flexible hemodynamic response function fitting and derivation, and reducing collinearity in the general linear model. We also provide four supplementary figures: S1: Derived hemodynamic response function; S2: Parametric regressors; S3: Unthresholded drug effect by condition; S4: Fitted responses in PPN voxels identified in Drug $\times$ Context interaction contrast. This material has not been peer reviewed.

\section{References}

Amanzio M, Pollo A, Maggi G, Benedetti F (2001) Response variability to analgesics: a role for non-specific activation of endogenous opioids. Pain 90:205-215.

Apkarian AV, Darbar A, Krauss BR, Gelnar PA, Szeverenyi NM (1999) Differentiating cortical areas related to pain perception from stimulus identification: temporal analysis of fMRI activity. J Neurophysiol 81:2956-2963.

Ashburner J, Friston KJ (2005) Unified segmentation. Neuroimage 260:839-851.

Atlas LY, Bolger N, Lindquist MA, Wager TD (2010) Brain Mediators of Predictive Cue Effects on Perceived Pain. J Neurosci 30:12964-12977.

Ballantyne JC, Mao J (2003) Opioid therapy for chronic pain. N Engl J Med 349:1943-1953.

Becerra L, Breiter HC, Wise R, Gonzalez RG, Borsook D (2001) Reward circuitry activation by noxious thermal stimuli. Neuron 32:927-946.

Beecher HK (1955) The powerful placebo. J Am Med Assoc 159:1602-1606.

Benedetti F, Amanzio M, Maggi G (1995) Potentiation of placebo analgesia by proglumide. Lancet 346:1231.

Benedetti F, Carlino E, Pollo A (2011) How placebos change the patient's brain. Neuropsychopharmacology 36:339-354.

Bergmann JF, Chassany O, Gandiol J, Deblois P, Kanis JA, Segrestaa JM, Caulin C, Dahan R (1994) A randomised clinical trial of the effect of informed consent on the analgesic activity of placebo and naproxen in cancer pain. Clin Trials Metaanal 29:41-47.

Bijur PE, Silver W, Gallagher EJ (2001) Reliability of the visual analog scale for measurement of acute pain. Acad Emerg Med 8:1153-1157.

Bingel U, Quante M, Knab R, Bromm B, Weiller C, Büchel C (2002) Subcortical structures involved in pain processing: evidence from single-trial fMRI. Pain 99:313-321.

Bingel U, Lorenz J, Schoell E, Weiller C, Büchel C (2006) Mechanisms of placebo analgesia: rACC recruitment of a subcortical antinociceptive network. Pain 120:8-15.

Bingel U, Wanigasekera V, Wiech K, Ni Mhuircheartaigh R, Lee MC, Ploner M, Tracey I (2011) The effect of treatment expectation on drug efficacy: imaging the analgesic benefit of the opioid remifentanil. Sci Transl Med 3:70ra14.

Brownstein MJ (1993) A brief history of opiates, opioid peptides, and opioid receptors. Proc Natl Acad Sci U S A 90:5391-5393.

Büchel C, Friston KJ (1997) Modulation of connectivity in visual pathways by attention: cortical interactions evaluated with structural equation modelling and fMRI. Cereb Cortex 7:768-778.

Buhle JT, Stevens BL, Friedman JJ, Wager TD (2012) Distraction and placebo: two separate routes to pain control. Psychol Sci 23:246-253.

Chapman CR, Casey KL, Dubner R, Foley KM, Gracely RH, Reading AE (1985) Pain measurement: an overview. Pain 22:1-31.

Cohen SP, Christo PJ, Wang S, Chen L, Stojanovic MP, Shields CH, Brummett C, Mao J (2008) The effect of opioid dose and treatment duration on the perception of a painful standardized clinical stimulus. Reg Anesth Pain Med 33:199-206.

Colloca L, Benedetti F (2009) Placebo analgesia induced by social observational learning. Pain 144:28-34.

Colloca L, Lopiano L, Lanotte M, Benedetti F (2004) Overt versus covert treatment for pain, anxiety, and Parkinson's disease. Lancet Neurol 3:679-684.

Craggs JG, Price DD, Verne GN, Perlstein WM (2007) Functional brain interactions that serve cognitive-affective processing during pain and placebo analgesia. Neuroimage 38:720-729.

Craggs JG, Price DD, Perlstein WM, Verne GN, Robinson ME (2008) The dynamic mechanisms of placebo induced analgesia: evidence of sustained and transient regional involvement. Pain 139:660-669.

Eippert F, Bingel U, Schoell ED, Yacubian J, Klinger R, Lorenz J, Büchel C (2009) Activation of the opioidergic descending pain control system underlies placebo analgesia. Neuron 63:533-543.

Flaten MA, Blumenthal TD (1999) Caffeine-associated stimuli elicit conditioned responses: an experimental model of the placebo effect. Psychopharmacology 145:105-112.

Gracely RH, Dubner R, McGrath PA (1979) Narcotic analgesia: fentanyl reduces the intensity but not the unpleasantness of painful tooth pulp sensations. Science 203:1261-1263.

Gracely RH, Dubner R, Wolskee PJ, Deeter WR (1983) Placebo and naloxone can alter post-surgical pain by separate mechanisms. Nature 306:264-265.

Gundersen H, Specht K, Grüner R, Ersland L, Hugdahl K (2008) Separating the effects of alcohol and expectancy on brain activation: an fMRI working memory study. Neuroimage 42:1587-1596.

Kirsch I, Lynn SJ, Vigorito M, Miller RR (2004) The role of cognition in classical and operant conditioning. J Clin Psychol 60:369-392. 
Kleijnen J, de Craen AJ, van Everdingen J, Krol L (1994) Placebo effect in double-blind clinical trials: a review of interactions with medications. Lancet 344:1347-1349.

Kong J, Gollub RL, Rosman IS, Webb JM, Vangel MG, Kirsch I, Kaptchuk TJ (2006) Brain activity associated with expectancy-enhanced placebo analgesia as measured by functional magnetic resonance imaging. J Neurosci 26:381-388.

Kong J, Kaptchuk TJ, Polich G, Kirsch I, Vangel M, Zyloney C, Rosen B, Gollub RL (2009a) An fMRI study on the interaction and dissociation between expectation of pain relief and acupuncture treatment. Neuroimage 47:1066-1076.

Kong J, Kaptchuk TJ, Polich G, Kirsch I, Vangel M, Zyloney C, Rosen B, Gollub R (2009b) Expectancy and treatment interactions: a dissociation between acupuncture analgesia and expectancy evoked placebo analgesia. Neuroimage 45:940-949.

Kupers RC, Konings H, Adriaensen H, Gybels JM (1991) Morphine differentially affects the sensory and affective pain ratings in neurogenic and idiopathic forms of pain. Pain 47:5-12.

Levine JD, Gordon NC (1984) Influence of the method of drug administration on analgesic response. Nature 312:755-756.

Levine JD, Gordon NC, Fields HL (1978) The mechanism of placebo analgesia. Lancet 2:654-657.

Lieberman MD, Jarcho JM, Berman S, Naliboff BD, Suyenobu BY, Mandelkern M, Mayer EA (2004) The neural correlates of placebo effects: a disruption account. Neuroimage 22:447-455.

Lindquist MA, Wager TD (2007) Validity and power in hemodynamic response modeling: a comparison study and a new approach. Hum Brain Mapp 28:764-784.

Lindquist M, Loh J, Atlas LY, Wager TD (2009) Modeling the hemodynamic response function in fMRI: efficiency, bias and mis-modeling. Neuroimage 45[1 Suppl]:S187-S198.

Martin MD, Ramsay DS, Whitney C, Fiset L, Weinstein P (1994) Topical anesthesia: differentiating the pharmacological and psychological contributions to efficacy. Anesth Prog 41:40-47.

Minto CF, Schnider TW, Shafer SL (1997a) Pharmacokinetics and pharmacodynamics of remifentanil. II. Model application. Anesthesiology $86: 24-33$

Minto CF, Schnider TW, Egan TD, Youngs E, Lemmens HJ, Gambus PL, Billard V, Hoke JF, Moore KH, Hermann DJ, Muir KT, Mandema JW, Shafer SL (1997b) Influence of age and gender on the pharmacokinetics and pharmacodynamics of remifentanil. I. Model development. Anesthesiology 86:10-23.

Penick SB, Fisher S (1965) Drug-set interaction: psychological and physiological effects of epinephrine under differential expectations. Psychosom Med 27:177-182.

Petrovic P, Kalso E, Petersson KM, Ingvar M (2002) Placebo and opioid analgesia-imaging a shared neuronal network. Science 295:1737-1740.

Ploghaus A, Narain C, Beckmann CF, Clare S, Bantick S, Wise R, Matthews PM, Rawlins JN, Tracey I (2001) Exacerbation of pain by anxiety is associated with activity in a hippocampal network. J Neurosci 21:9896-9903.

Price DD, Von der Gruen A, Miller J, Rafii A, Price C (1985) A psychophysical analysis of morphine analgesia. Pain 22:261-269.
Price DD, Craggs J, Verne GN, Perlstein WM, Robinson ME (2007) Placebo analgesia is accompanied by large reductions in pain-related brain activity in irritable bowel syndrome patients. Pain 127:63-72.

Rohsenow DJ, Marlatt GA (1981) The balanced placebo design: methodological considerations. Addict Behav 6:107-122.

Ross S, Krugman A, Lyerly S, Clyde D (1962) Drugs and placebos: a model design. Psychol Rep 10:383-392.

Schweinhardt P, Seminowicz DA, Jaeger E, Duncan GH, Bushnell MC (2009) The anatomy of the mesolimbic reward system: a link between personality and the placebo analgesic response. J Neurosci 29:4882-4887.

Shattuck DW, Mirza M, Adisetiyo V, Hojatkashani C, Salamon G, Narr KL, Poldrack RA, Bilder RM, Toga AW (2008) Construction of a 3D probabilistic atlas of human cortical structures. Neuroimage 39:1064-1080.

Sternberg S (1969) Memory-scanning: mental processes revealed by reaction-time experiments. Am Sci 57:421-457.

Volkow ND, Wang GJ, Ma Y, Fowler JS, Zhu W, Maynard L, Telang F, Vaska P, Ding YS, Wong C, Swanson JM (2003) Expectation enhances the regional brain metabolic and the reinforcing effects of stimulants in cocaine abusers. J Neurosci 23:11461-11468.

Wager TD, Fields H (2012) Placebo analgesia. In: Wall and Melzack's textbook of pain, Ed 6 (McMahon SB, Koltzenburg M, eds), In press. Philadelphia: Churchill Livingstone.

Wager TD, Rilling JK, Smith EE, Sokolik A, Casey KL, Davidson RJ, Kosslyn SM, Rose RM, Cohen JD (2004) Placebo-induced changes in FMRI in the anticipation and experience of pain. Science 303:1162-1167.

Wager TD, Keller MC, Lacey SC, Jonides J (2005) Increased sensitivity in neuroimaging analyses using robust regression. Neuroimage 26:99-113.

Wager TD, Scott DJ, Zubieta JK (2007a) Placebo effects on human $\mu$-opioid activity during pain. Proc Natl Acad Sci U S A 104:11056-11061.

Wager TD, Lindquist M, Kaplan L (2007b) Meta-analysis of functional neuroimaging data: current and future directions. Soc Cogn Affect Neurosci 2:150-158

Wager TD, Atlas LY, Leotti LA, Rilling JK (2011) Predicting individual differences in placebo analgesia: contributions of brain activity during anticipation and pain experience. J Neurosci 31:439-452.

Watson A, El-Deredy W, Iannetti GD, Lloyd D, Tracey I, Vogt BA, Nadeau V, Jones AK (2009) Placebo conditioning and placebo analgesia modulate a common brain network during pain anticipation and perception. Pain 145:24-30.

Wise RG, Rogers R, Painter D, Bantick S, Ploghaus A, Williams P, Rapeport G, Tracey I (2002) Combining fMRI with a pharmacokinetic model to determine which brain areas activated by painful stimulation are specifically modulated by remifentanil. Neuroimage 16:999-1014.

Wise RG, Williams P, Tracey I (2004) Using fMRI to quantify the time dependence of remifentanil analgesia in the human brain. Neuropsychopharmacology 29:626-635.

Yang JC, Clark WC, Ngai SH, Berkowitz BA, Spector S (1979) Analgesic action and pharmacokinetics of morphine and diazepam in man: an evaluation by sensory decision theory. Anesthesiology 51:495-502.

Zubieta JK, Bueller JA, Jackson LR, Scott DJ, Xu J, Koeppe RA, Nichols TE, Stohler CS (2005) Placebo Effects Mediated by Endogenous Opioid Activity on $\mu$-Opioid Receptors. J Neurosci 25:7754-7762. 